\title{
Customers' Perception on the Trustworthiness of Electronic Commerce: A Qualitative Study
}

\author{
John Uy \\ Ivan Opalla \\ RheaLyn Cabasa \\ Melyza Palacio \\ Maria Torrefiel \\ Alyssa Cabantud \\ April Cabezas \\ Louiez Magnaye \\ Mhycah Maluenda \\ Lea Fernandez
}

March 2019

Correspondence:

Ivan Louie Opalla

Team Leader

University of Immaculate Conception

Annex Campus

Bonifacio St., Davao City 8000

Davao del Sur, Philippines

(082) 2271573

(082) 2273794 


\begin{abstract}
Electronic commerce is growing popular across the world because of the convenience it brings to online sellers and online customers. However, as the electronic commerce rises, problematic issues like privacy concerns, dissatisfaction, incompetent deliveries, and the most important - trust issues - also surface. Numerous previous studies indicated that the purchase intention and behavior of the online customers depend on their perceived risk and shopping experience in electronic commerce. Some studies also specifically stated that personal information, product quality, security, and business reputation are the usual factors which the customers evaluate to deem the online business as trustworthy. The researchers conduct this qualitative study concentrated on the perceived trustworthiness of e-commerce to know if it complements the results of other studies and to provide information to online users which can guide them in either selling or purchasing products online. Using purposive sampling and thematic data analysis, the researchers had eight in competence area, three in benevolence, and two in integrity as determining factors on the online business' trustworthiness. The findings of the study claimed that online customers value the competence, benevolence, and integrity of the online business to be perceived as a trustworthy one.
\end{abstract}

Keywords: electronic commerce, e-commerce, online customers, trustworthiness 


\section{INTRODUCTION}

\section{Background of the Study}

Electronic commerce, or e-commerce, is the act of merchandising and purchasing of products or transferring of money using various electronic means mainly by the internet and mobile applications (Rouse, 2019). Although growing popular among the mass, electronic commerce still faced numerous difficulties in online shopping, affecting both online sellers and online customers. According to Tamturk (2017), global netizens who can access via internet had hesitations in engaging in an online business, due to privacy and security concerns, which obstructed the growth and development of the digital market. Customers in America tended to buy produce which they can physically test by touching and examining the product to personally scrutinize its quality and durability (Shoup, 2018). This preference by American customers resulted to the emergence of the need for the online sellers to develop the shopping experience for the online consumers, promote cost savings, and present comprehensive information about the product to establish trust in the online transaction and convey the product's quality. Additionally, online customers in India suffered poor product delivery in shopping online. As stated by Sivanesan (2017), Indian online customers often faced problems in this phase of shopping as they usually had to wait for their ordered product with a week of delay or more. Winnie (2014) added that trustworthiness played a pivotal role in Malaysian online context for it increased the satisfaction of the customers in online shopping; hence, increasing the level of loyalty for the customers to shop online. In a nutshell, trust was a critical component in the world of international electronic commerce. Online sellers must, then, improve the product information they presented and consider the profiles of their customers.

In the national context, e-commerce in the Philippines was deemed as a rising trend in business due to the adoption of mobile technologies particularly by the young users (Vicente, 2016). Despite this growing popularity and acceptance in the country, it was not exempted from the common problems. As stated by 
Segovia (2016), e-commerce was falling behind despite its fast acceleration in the Philippines. One of the reasons was the lack of establishment in the infrastructure which commonly involved the connectivity of the internet, electronic payments, regulatory environment, and logistics. Internet problems were also present as hindrances towards the further blooming of e-commerce in the Philippines. These internet problems were the slow yet costly internet connection, internet hoaxes, the absence of internet connectivity, and internet hacking (Diangson, 2014). Also, Toral (2016), indicated that delivery delays were depressing the Philippines' ecommerce sector. Various complaints from customers surfaced due to these distressing delivery delays induced by the traffic, weather, and primarily by the scarcity of courier providers. Another problem faced by the Philippines' ecommerce sector was trustworthiness issues. Domingo (2017), reported that trust issues were holding back the development and growth of the country's electronic commerce as distrust was still in the minds of the people. Most of the Filipinos were afraid that they would get conned or scammed by online shopping sites which caused their doubt towards this electronic commerce.

Meanwhile, in the local aspect, small business owners' profits were raised due to the tapping of the advancement of technologies, most especially the internet (Cayon, 2018). Around two hundred and forty-eight (248) micro-small businesses boosted because of its affiliation to the social media and internet. Moreover, the use of Facebook had been tapped by the Davao City Agriculturist Office (DCAO) as the medium of negotiation which could be useful for the interested people in agriculture (Jara, 2018). This practice of using social media channel was beneficial to the farmers and producers so that they could showcase and endorse their products and goods. In terms of e-commerce among the business owners, it was said that competitions among online businesses were rising in Davao City (Bagaforo, 2017). Some entrepreneurs tried to sell on different cities only to discover that other cities did not embrace electronic commerce, in comparison to the Davao Region. However, behind this expanding market, problems still arose. These problems include the slow internet connection which the internet users had to deal with; thus, compelling them to pay 1.5 times more just to experience the 
same speed of internet connection in Luzon areas like Makati (Marcelo, 2018). To sum it all, electronic commerce is a type of business which uses the internet to make transactions and it is continuously expanding. Behind this widespread popularity, common and problematic issues slowly ascended, from the international aspect to the local context. These common problems such as trust issues, privacy concerns, delayed deliveries, slow internet connection, and lack of interaction towards the user and the product prompted the researchers to make a study about the customers' perception in terms of the trustworthiness of electronic commerce for it could alleviate the difficulties experienced by the customers and online retailers in online shopping.

A previous study was conducted by Pennanen and Paakki (2006), about the perceptions of the customers towards electronic commerce. Their results focused mainly on the competence dimension of the online business among the other two factors which are the integrity dimension and benevolence dimension. Their study focused on the insights of the customers about electronic commerce and its services to its customers. The results of the interviews showed that the customers were satisfied in the payment systems and delivery systems of the marketers, as well as their responses to the feedbacks of the customers. Despite their few problems regarding the abrupt and uncalled change of product delivery, the overall results pointed out that electronic commerce was satisfactory for online customers. Another study on the same year conducted by Zhang and Tang enumerated the five dimensions that would affect the perceptions of the customers towards e-commerce and its quality as a business. The five dimensions were stated as all influencing and vital factors towards the customers, and they were website design, reliability, responsiveness, trust, and personalization. These five dimensions all revolved around the usability, dependability, and convenient experience it would give to the customers that would increase their level of trust and satisfaction towards electronic commerce.

There were numerous previous studies and researches about electronic commerce - apprehending its advantages and impact to the advancing 
community. As for this study, the researchers wanted to delve specifically on the online customers' perceptions about e-commerce. The researchers wanted to know if the findings of this study is parallel to the results of other researches concerning the trustworthiness of online business. In this way, it could either contribute to a bigger area of knowledge or reveal a new one. About the customers' perception, the researchers also wanted to focus on the trustworthiness trait that every online business should possess. This study could both benefit the online customers and the online sellers as it could give knowledge and initial idea to the former one who would like to try online shopping. On the other hand, this study could help the latter in improving their businesses from the common problems they face through the results presented in this study. The findings could also be a guide for aspiring online entrepreneurs in making their own business in the future. Additionally, this study could help the general people and future researchers in providing knowledge and information about this developing e-commerce.

In all, this research intended to solve the previously mentioned issues about electronic commerce which mainly dwelled on the trustworthiness, privacy, security, and inconvenience of the online shopping sites. Apprehending the customers' perception could aid the problems which most of the online customers and online sellers face for it could determine the root cause of the common difficulties, and it could provide solutions to these problems.

\section{Purpose of the Study}

The primary purpose of this study was to help internet users in the field of electronic commerce. To achieve this, the researchers specifically intended to know the views and insights of electronic commerce from the perspective of the customers. The researchers wanted to focus on the reliability, convenience, and trustworthiness of the online businesses based on the customers' shopping experience. Additionally, the researchers planned to have results which could be useful in alleviating the ignorance of new online customers. The researchers also 
aimed to help the online business owners in devising beneficial strategies and techniques which could raise the sales of their businesses. Other than understanding the perceptions of the customers, this study purposed to guide the online sellers in selling their products. Furthermore, this research sought to help the future researchers in their studies concerning electronic commerce, especially in this generation that the advancement of technologies was rapid, and people continuously accept and adopt these innovations. Lastly, this study sought to be a contribution to the general academic knowledge in the field of business which could facilitate the questions and concerns of the general people.

\section{Research Questions}

This study aims to know the insights of the customers who already have enough experience in online shopping, to guide other customers towards online shopping, to help the online business owners, and to provide information to the netizens. Specifically, it attempts to answer the following question:

1. What are the customers' perceptions on the trustworthiness of electronic commerce?

\section{Theoretical Lens}

This qualitative study focused mainly on online business then the online shoppers' perceptions about online business. Online shopping researches had produced theories relating to adoption, acceptance, and consumers' buying behavior. The theories involved are: 1.) Commitment-Trust Theory of Relationship Marketing, 2.) Source Credibility Theory, and 3.) Grounded Theory of Online Shopping Flow.

The Commitment-Trust Theory of Relationship Marketing claims that trust and commitment must be present for a relationship to be successful (Mack, n.d.). 
Trust and commitment are two of the fundamental factors in relationship marketing. The businesses need to neglect the possibilities of having short-term profit and acknowledge the principles of relationship marketing, which is mainly to satisfy the needs of the customers and recognizing their commitment towards the business. Following this theory would bring satisfaction and fulfillment for both parties. The customers do not only receive the product, but also feel that they are honored by the business. In return, the business acquires the loyalty of the customers. Commitment-Trust Theory can be related in the researchers' study by thinking that the electronic commerce must be relationship-based for them to be viewed as trustworthy through the eyes of the customers; hence, giving the online business customer loyalty. This theory can be used by the researchers in a way that the findings in the study can contribute to this theory. Furthermore, this theory can state that in the context of electronic commerce, the online businesses must not only satisfy their customers but also acknowledge their presence in order for them to have long-term profit with the presence of the loyalty of the customers.

Source Credibility Theory states that in a communication process, the receiver of the message believes the message basing from the perceived credibility of the source (Umeogu, 2012). For an instance, a sender transmits a message towards the receiver. The receiver believes the message of the sender because the receiver perceives the sender as credible and trustworthy. If the receiver perceives the sender as dishonest, then the receiver would not believe nor acknowledge the message. This theory can be paralleled on the relationship between the online seller and the online customer. The relationship between the two could be rooted from the credibility of the online seller which specifically includes how the seller conveys the product information towards the customer and how accurate the information matches the actual product. Moreover, this theory could be applied in this study by having this theory as one of the reasons why the customers perceive electronic commerce as either trustworthy or not.

Lastly, grounded theory was developed from the study of Mahnke, Benlian, and Hess (2015). Their grounded theory discussed the flow or sequence of events 
in the context of online shopping. The findings of their study affirmed that the quality and quantity of information were crucial requirements in the said context of online shopping. The theory also related other theoretical relationships in online business specifically website design and flow of experience. Their grounded theory could also be applied to the researchers' topic for the reason that the theory itself discussed the flow of experiences of users in the online shopping context. Consumers' experiences in buying products online were the basis of their perceptions whether electronic commerce was trustworthy or not. This grounded theory of Mahnke et al. in 2015 could complement the experiences of the consumers since the theory focused mainly on the flow of experience in the context of electronic commerce. Also, this grounded theory could complement the findings of the study for the perceived trustworthiness of online businesses could be grounded from its establishment which is the main factor which affects the online shopping experience of online customers.

\section{Review of the Related Literature}

\section{Defining Electronic Commerce}

On the review of Shafiyah, R. Alsaqour, Shaker, O. Alsaqour, and Uddin (2013), about electronic commerce, they defined electronic commerce or ecommerce as the upholding of business affiliations, disclosing business information, and making business negotiations using telecommunication networks such as the internet. The emergence of this type of business made gradual yet drastic changes in the economies on most of the countries across the globe. It helped the people in purchasing products with fewer cost and effort. It also helped the business-minded people in reducing their work yet earning a profit by giving them a virtual space for their stores by setting an actual and physical one. Also, ecommerce aided the citizens in providing job opportunities from different fields like entrepreneurial studies, management, and marketing. Their review also enumerated the striking features of electronic commerce which includes ubiquity, richness, interactivity, personalization and customization, global reach, universal 
standards and information density. These features showcased why electronic commerce is growing popular and widely accepted by the people. Although, the researchers still indicated some problems in this developing e-commerce namely cultural obstacles and legal challenges, despite those, they concluded electronic commerce as one who could deal an extraordinary change in the world.

Another study by Vaghela (2014), stated that online shopping is a method of shopping for goods and offerings from dealers who promote and sell their products and services in internet. Since the World Wide Web (WWW) emerged, retailers have found a way to sell their merchandise to people who surf the internet. Shoppers can visit internet shops from the convenience of their home and relax as they shop in front of their computers. Today, online shopping has come to be popular among people; they have been very cozy in using the internet and turned out to be technology experts. The increasing popularity of online shopping among the people prompted the researchers to study the utilization of electronic commerce and the perception of the people towards it. This study sought to discover the standpoint of online buyers towards online shopping and also distinguish this perception of gender vise. This study gathered data and analyzed that customers see purchasing online as way better than manual shopping and most of the online buyers are fulfilled with their online buying transactions. Online buyers access their internet on their home, office, and school. Most of the customers shop for accessories, clothes, and electronic appliances. Providing their credit card number and not seeing the products personally, are the most alarming barriers of online shopping. Customers agree with the fact that purchasing online is costly than manual shopping and it takes extra time for their purchases to be delivered to them.

Internationally, Peng (2018), in their study, affirmed that internet shopping has investigated essentially worldwide over the most recent couple of years. Taiwan is no exceptional case. May despite that Taiwan has encountered a development in internet shopping, it seems to linger behind whatever is left of the created nations in Asia. Concentrate on the variables which impact purchaser's 
web-based shopping trust, and fulfillment is in this way focal all together for Taiwan merchants to build up the proper techniques for online exchanges. This paper seeks to perceive what are the primary components of the purchaser's expectations to repurchase online in Taiwan; grounded chiefly on hypothetical models, for example, Technology Acceptance Model (TAM) this investigation extraordinarily points to perceive whether there are relations between buyer's repurchase aim and saw value, seen usability, saw security, buyers' trust, and shoppers' fulfillment. An overview was led with 225 legitimate buyers from Taiwan utilizing an organized self-managed poll and information was broke down utilizing Partial Least Squares (PLS) Structural Equation Modeling (SEM). From the outcomes, we accomplished new experimental proof for applying trust and fulfillment for considering shopper repurchases goal. The results demonstrate that apparent value, and saw usability, utilize huge positive effect on customers' trust. Thus, fulfillment is affected by apparent handiness, perceived convenience, and perceived protection, which by implication impacts repurchase aim of the customers. Hence, the online retailer must focus on the mechanical qualities of their shopping site to decrease the protection worry of purchasers concerning unapproved access and auxiliary utilization of their own and money related information that can make strides buyer trust and fulfillment towards shopping site, and lead to repurchase expectation.

\section{Positive Effect of E-commerce}

The emergence of electronic commerce generated some effects and benefits, especially in the perspective of the customers. As stated by Khan (2016), on his study about the impact of e-commerce in a developing economy, the significant benefit of e-commerce through the eyes of the online customers was that they could conserve their time as they could easily access the online business wherever they want and order a product whenever it is suitable for them. Besides, the customers who were not really into social discourse could be comfortable for this business did not require personal interaction with the online business 
providers. The customers could also easily switch from one online business site to another without anyone intervening them if the business from one online business did not meet their satisfaction. Moreover, some products which were not yet released in the physical market could be purchased online; hence, this gave them broader access to the products in comparison before. The customers had also wider access of product data from the reported information of the products by the business to the posted online reviews of the products or the business site itself. This research went well to another study of Ozlen, Mekic, and Kumbara (2014), as they also indicated that the adoption and acceptance of electronic commerce gave an advantage for the customers to buy products online wisely mainly by having comprehensive access to the information of the products offered by the businesses. Having a more informative product information helped them in their decision-making, taking into consideration other available products as alternatives if a specific product is insufficient for them.

\section{Negative Effects of E-commerce}

Despite these advantages and benefits, online customers also experience problems and inconvenience while shopping online which could also affect their perceptions towards electronic commerce. Sivanesan (2017), said that online customers commonly suffer from the transaction and delivery of the products ordered. Sivanesan further explained that the delivery point did not reach the area of the customers which resulted in the delay of delivery. The customers had to wait for a week. Product information and quality were also insufficient for the customers as they would sometimes receive damaged goods or defective products. Karthikeyan (2016), added that the customers were also facing defective products, refund issues, and lack of response to customer care, apart from the delivery issues. Khan (2016), continued to enumerate these problems experienced by customers. Khan stated that the lack of security, standards, and protocol of online businesses led to the loss of the customers' money. Furthermore, customers also deal with the high price of having an internet connection. Lastly, the most 
significant factor customers had to face is the trust issues. These trust issues encompass mainly on the rules and judicial adjustments which can make the online transactions of electronic commerce invalid and technically illegal.

\section{Trustworthiness in E-commerce}

Concerning the trustworthiness of electronic commerce, given the good and adverse effects of e-commerce, trust plays a pivotal role in both for customers and the online sellers. Trust is one of the essential elements of human emotions (Winnie, 2014). It is also one of the essential factors in electronic commerce for this is affects the purchase intention and motivation of the online customers towards the online business and its product offering. According to Lanford and Hübscher (2014), the guidelines that would help the online websites to be called as a trustworthy site are to satisfy the expectations of the customers, to manifest technical abilities and competence, and to prioritize the interests of the customers. Reducing the possible risk that would be encountered by the customers, asking the private information of the customers only if necessary, and establishing a good image are also part of the guidelines. These guidelines were the basis of the trust of the customers in building a relationship with the business and having an interest in purchasing the products. Panula (2017), in her study, added that the website, and its product and business information must possess clarity and discoverability to boost the level of trust of the customers to the business. Finally, trustworthiness relied on the service of the electronic commerce to online customers, quick deliveries, and fast responses from feedbacks.

Moreover, Kim, Ferrin, and Rao (2008), stated that the online buyers' purchase decisions were highly impacted by their reliance and perceived risk towards an online store. Online buyers' decisions and their trusts to a marketing website were highly influenced by their dispositions on the reliability, image, security, privacy, the authenticity of the marketing website, and the overall online market's reputation. Interestingly, in this study, the third-party seal or the 
customers' review and assurance seal did not have or leave a significant effect and influence on the customers' trust towards the marketing website.

However, according to Utz, Kerkhof and Bos (2011), the store reputation had no significant effect on the consumers' purchase decisions. In the two experiments conducted, the roles of dispositional trust were also examined. In experiment 1 the perceived trustworthiness was mainly influenced by the dispositional trust. While in experiment 2, the dispositional trust inhibited the outcome of assurance and reviews. Online stores are most likely to gain high trust because of the influence of customers' review. The findings of this research tell that the remarks and comments of the consumers give assurance and greatly affects consumer decision making.

Another related study by Changchit (2006), stated that there were five factors which were perceived by the customers as either good for the online business which encouraged them to continue shopping online or poor for the online sites which made the customers stick to the brick and mortar stores. The factors were perceived risk with online shopping, perceived ease of online shopping, experience with online shopping, perceived benefits of online shopping and perceived uncertainty of online shopping. The factors that resulted to higher rates by the respondents were the perceived ease, experience, and perceived benefits of online shopping. These results pointed out that these are rated by the customers who experienced and viewed online shopping as a convenient way of buying products. On the other hand, the remaining factors namely the perceived risk and perceived uncertainty of online shopping got lower rates by the respondents that only showed that there were customers who faced these problems while shopping online. The results, then, suggested that online business providers should maximize their security in their online businesses. Also, they must inflict to the customers the feeling that they are certain while buying online, specifically by assuring the delivery dates and methods and having a return policy with ease. 


\section{Online Customers' Perceptions of E-commerce}

Now, the results of the study of Pennanen and Paakki (2006), falls on the positive side of the perceptions of the customers about electronic commerce. The impression of the customers towards the trustworthiness of electronic commerce mainly circles its competence dimension or the assumption of the vendor that the online business has all its products offered on its website. Based on the study's findings, the customers deemed the payment systems adequate and satisfactory. The delivery method and service were also impressive as what their interviewees said. In terms of the withdrawal of the order, the customers expect that they could cancel their offer since it was stated in the consumer protection law. Although, disappointing and annoying situations still arise like the sudden change of product delivered without the customer's permission. These situations were perceived as incompetent for the participants who are the customers. In addition to this, the accuracy of the delivery time and the quality of the products were not commendable. Other dimensions were also connected such as the benevolence and integrity dimensions. The interviewees commented that online businesses usually respond positively when the customers give feedback. Also, they agreed to get their personal information as long as it would not be used for other agenda, having their final say that reliability of the business is what they considered as the most noteworthy feature. In summary, the study's results indicated that customers perceived the trustworthiness of the e-commerce more from its competence in comparison to its benevolence and integrity.

In contrast to the Pennanen and Paakki's (2006) qualitative study, Folarin and Ogundare's (2016) quantitative study affirmed that customers are still doubtful to this emerging electronic commerce. Their study inferred their conceptual framework from previous studies and ended into tapping five variables which include delivery risk, financial risk, information privacy risk, quality risk, and security risk as determinants on the online customers' shopping intention and perceived trust towards the e-commerce. Questionnaires were given to three hundred and seven respondents who were online customers to solicit the data 
needed. Their statistical results narrowed down three variables of risks which instigated the preference of the customers of brick and mortar stores over electronic commerce. These three risks are financial risk, information privacy risk, and quality risk. The results showed that customers were afraid of incurring financial loss as they were not assured that the product, they purchased would perform the way they expected it, given that there was no return policy implemented. Additionally, the lack of interaction between the customers and the product itself made them more reluctant and doubtful in the virtual environment. This problem was even intensified by the lack of product information and insufficient pictures presented by the online business. Lastly, the customers felt not safe and secured in giving their personal information for the fear that it will be used against their favor or without their permission. These variables laid out in this study must be taken into attention and action by the online sellers to increase the number of their customers and increase the customers' level of trustworthiness to electronic commerce.

Furthermore, the study of Belanger, et al. (2002), agrees and states that while the development of business-to-shopper electronic trade appears to be amazing as of late, a few investigations propose that an expansive number of people utilizing the Internet have genuine security concerns, and that triumphant open trust is the essential obstacle to proceed with development in online business. This examination explored the relative significance when obtaining merchandise and ventures over the Web, of four common trust records (for example (1) outsider protection seals, (2) protection articulations, (3) outsider security seals, and (4) security highlights). The outcomes show buyers esteemed security includes fundamentally more than the three other trust files. We additionally examined the connection between these trust files and the buyer's view of an advertiser's reliability. The discoveries demonstrate that shoppers' appraisals of the reliability of Web traders did not parallel specialists' assessment of locales' utilization of the trust files. This investigation likewise analyzed the degree to which shoppers are eager to give private data to electronic and arrive traders. The outcomes uncovered that when settling on the choice to give private 
data, buyers depend on their view of reliability regardless of whether the dealer is electronic just or arrive and electronic. At long last, we examined the general significance of three kinds of Web traits: security, protection and delight highlights (accommodation, convenience, beauty care products). Protection and security highlights were of lesser significance than joy highlights while thinking about customers' goal to buy. A dialog of the ramifications of these outcomes and a motivation for future research are given.

Lastly, the perceptions of the customers towards e-commerce and its quality were grounded from its website design, reliability, responsiveness, trust, and personalization. Website design is the foundation of the information and accessibility of the online business and its products. Website design could also be a vital factor for the customers who were easily attracted and affected by the site's aesthetic characteristics. Reliability, on the other hand, also plays a pivotal role in the perceptions of the customers. It could be a very influencing drive for the customers. Reliability grounds from the accuracy of the information, the fulfillment of the agreed delivery time and method, and the integrity of the business towards its customers' private information. Responsiveness helped in building the virtual interaction between the buyer and the seller, whereas trust is also a vital dimension. Lastly, personalization satisfies the distinct needs of the customer as an individual. These five dimensions affect the perceptions of the customers towards electronic commerce (Zhang \& Tang, 2006). 


\section{METHODOLOGY}

This chapter presents the methodologies and processes used to conduct the study. It discusses how the researchers will gather the information that will be used. It also shows who will be the participants of the research.

\section{Research Design}

This research is a qualitative study; it is associated with a phenomenological approach to collect relevant data. This approach concerns with understanding and interpreting the information that the participants gave based on their daily lives (De Vos, 1998). Also, the qualitative approach focuses on the qualities of human behavior (Ferreira, Mounton, Puth, Schurink \& Schurink, 1998). This study aims to comprehend and interpret the intentions that underlie in humans' everyday action (Bailey, 1998; Bogdon \& Taylor, 1975; De Vos, 1998, Ferriera, et al.,1998).

Qualitative design deals with results that are orally transmitted and derives meaning from the perspectives of the participants (Bless and Hugson-Son,1995; De Vos, 1998). The purpose of this design is to analyze the idea and experiences of the participants associated with their daily lives. The qualitative approach is suitable in the researchers' study because the collected data focuses on the participants' lives through verbal communication and the way they convey them. Marshall and Rossman (1995) stated that this approach is appropriate to reveal the unknown and to explore new ideas.

\section{Sampling Method}

A non-probability or non-random sampling technique called purposive sample was utilized to pick up a sample of participants who provided enough information which is useful for this qualitative study. Purposive sampling is a sampling method that selects the sample based on the attributes of a population 
and based on the goals of the research (Crossman, 2018). Purposive sampling could also be called as judgmental, selective, or subjective sampling. This sampling technique is functional in this study for the researchers to have information-rich information related to the topic of the study (Palinkas, Horwitz, Green, and Wisdom, 2013). Then, the researchers sought for participants who are discerned to be rich in information and are suitable for the study. The researchers gathered a sample of people from diverse backgrounds to have differing results and information, and to comprehend the research topic deeply.

\section{Participants}

The researchers reached out and invited the expected participants to take part in the study. The prospective participants have presented a sheet of information. They were informed by the researchers that the participation is voluntary and that they have the right to decline the interview. After the participants agreed to take part, they were further reminded that they have the right to pull out from the interviewing process. Also, they were informed that the interview is private and the information that the participants have provided would be handled with confidentiality. Lastly, they were made aware that it is not necessary to reveal their identification details.

The researchers chose ten (10) participants aged $17-41$; two (2) male and eight (8) female who have insights on online shopping from their shopping experiences.

\section{Research Instrument}

In this phenomenological study, the research questions were formulated by the researchers. Mr. Joseph Dave M. Pregoner, the validator, will first evaluate and validate the questions devised by the researchers. After it is validated, the questions will undergo trial. In this qualitative phenomenological study, the 
instrument which will be employed is interview questions and will be using tapedrecording for authenticity purposes.

The interviewer would ask the questions in English and would also provide a translator for the participant to further understand the question. The participant can use the language he or she is comfortable with to be able to express themselves openly and freely without distrust.

\section{Data Collection Method}

Information and data were collected using face-to-face individual interview schedule. According to Kvale (1996), an interview is the act of collecting descriptions and pieces of information about the interviewee's lived experiences through conversation. Additionally, in-depth interviews are powerful in eliciting narrative data for the researchers to be able to explore other peoples' view in greater understanding. The researchers used a semi-structured interview, which means that the questions and concerns to be argued and discussed were already prepared before the interviewing process. Semi-structured interviewing lets the interviewer expound and discuss the important points of the issue that uprises during interviews. The researchers developed the questions to suit the participants' comprehension. Non-verbal communications and reactions were read by the researchers through a face-to-face interview, and this proved to help in data analysis. The conducted interviews were audio-recorded then transcribed by the researchers.

Dörnyei (2007) noted that natural flow and richness in details are the two key features to have an excellent qualitative interview. To achieve this, the researchers must not forget that they conduct an interview not just to ask but also to listen. This interviewing attitude helps to build trust between the researcher and the participant. The researchers were also cautious in terms of emotional engagement to retain the validity, credibility, and the reliability of the study. (Ferreira, 1988). The responsibility of the interviewer should establish an 
appropriate atmosphere wherein the interviewees would feel more at ease and can talk freely and openly (Richards, 2003).

\section{Data Analysis Method}

The thematic content analysis method is used to analyze the results. Ezzy (2000), describes this method of data analysis as a way of analyzing and interpreting data by organizing and classifying it into categories based on themes, concepts or similar features. The procedures used are designed to compress and categorize large quantities of data into more meaningful units for interpretation (Singleton, 1997). The following steps used in developing themes were informed by Marshall \& Rossman (1989) and De Vos (1998).

\section{Organizing data:}

In order to be familiar with the data, the researchers repetitively read the transcribed data.

\section{Generating categories, themes, and patterns:}

Creative and analytical thinking is required in this stage. The researchers determine the most essential themes, recurring ideas, and patterns of belief, which assisted with the forming of the results. The process of category generation involved noting patterns in the research participants. As categories of meaning surfaced, the researchers sought for those that were internally consistent but different from each other. Patterns, themes and categories were uncovered.

\section{Testing emergent hypotheses:}

If categories and pattern became apparent in the data, the researchers would evaluate the credibility of developing hypotheses, and they would test them against the data. Informational adequacy, credibility, usefulness, and centrality will be involved in assessing the data. 


\section{Searching for alternative explanations:}

When the categories and patterns emerged in the data, researchers are involved in the patterns that seemed apparent. Reasonable explanations were looked and describe until the researchers will reach it.

\section{Report the results:}

As the researchers report the results, it gives shape, interpretation, and meaning to the chunks of raw data.

\section{Trustworthiness of the Study}

As this qualitative study was conducted, the researchers introduced letters to the ten (10) participants. These letters state that whatever data assembled and utilized would only be used for the study and would be treated with the utmost security and confidentiality. To build up reliability, this research ought to have credibility, transferability, dependability, and conformability. In terms of validity, the researchers were sure that this study is valid since they could recognize right operational measures for the ideas being examined (Pandey and Patnaik, 2014) which, for this situation, is the interview since interview is helpful in getting the background and environmental context of the participants, and it can give comprehensive information about the subject (Mcnamara, 1999).

The researchers were positive in terms of the credibility of the results of this study since the ten (10) participants were online customers who utilized electronic business. The researchers were aware of the moral thought in interviewing the participants. The participants could convey their insights without intrusions from the researchers. Lincon and Guba (1985), attested that it is the researchers' job to give enough and relevant background about the research to give transferability. To employ transferability, the researchers will give a substantial description; a term authored by Geertz (1973) which recommend that research ought to have accurate data as well as rich discourse and translations. The researchers will provide 
specified and improved details, on account of documented experiences. To set up dependability as stated by Lincoln and Guba (1985), a researcher should utilize inquiry audit. The purpose of doing this is to assess the precision and to assess whether the interpretations, final statements, and discoveries are bolstered by the gathered information. The researchers were certain that any form of biases is not tolerated and done all through the inquiry in order to build up conformability. The method for making inquiries was done with full respect. The researchers guarantee that whatever data accumulated in this study are not fabricated nor distorted. After the transcription of the participants' responses, the participants checked it, and they are approached to sign on the lower right segment if everything printed was correct as an indication of legitimacy. Lastly, the researchers guaranteed the respondents that their identities would be private.

\section{Ethical Considerations}

Informed consents were asked from the participants subsequently after they agreed to be in part of the researchers' study. This ethical process was attained by reading to the participants the informed consents and requesting them to validate their consents by putting their signature on the consent. They were also oriented about the clause of confidentiality. This confidentiality indicates that the dignity of the participants must be considered and respected. Thus, it is essential that the participants are not reluctant and doubtful about the security and confidentiality of the information that they would share (Ferreira, et al., 1988). They were also oriented that private information would only be accessed by the researchers and their supervisor. Also, they were not obliged to share some pieces of information or details that would cross their privacy even if some participants personally agreed to disclose their information in the printed materials. After the transcription, the audio-tapes were secured and kept in private. After the study had been fully and successfully completed, the audio-tapes would be eradicated. 


\section{Role of the Researcher}

In this study, the researchers play an important role in terms of facilitating the research procedures to have an organized process. The researchers would assure that all their biases would be disregarded during the interview and transcribing method. They would analyze the gathered data and remove unnecessary words. The researchers would also filter all statements to identify if these findings will be denied or accepted. To make the information more reliable, the researchers would construct and translate the structural theme into a general theme. By these, they would be able to know and understand the life experiences of their participants in online shopping. 


\section{RESULTS AND DISCUSSION}

This chapter has been formulated to answer the research question keeping the literature review and research findings from the interviews in consideration.

Research Question 1: What are the customers' perceptions on the trustworthiness of electronic commerce?

The interviews sought to elicit the participants' perceptions on the trustworthiness of electronic commerce. After various processes of data, coding, three themes of trustworthiness were formulated.

In the presentation of the findings below, the themes are given as headlines in bold and the subthemes are marked in italics within the text. Quotations from the participants are interspersed to ground the presentation in the participants' accounts.

\section{Competence}

Competence means that someone can believe that the other party has the ability to do what is agreed (Derwik \& Hellstrom, 2017). In the context of electronic commerce this means, for example, that the customer can be sure that the electronic vendor has all the products available that are offered on their web site (Cox, 2001). The findings of the study indicate that most of the issues concerning trustworthiness of an electronic commerce appear in the competence dimension. Altogether, eight different competence-related issues appeared in the interviews. Two of them were sufficient payment methods and home delivery of the products. The participants were satisfied because they felt the electronic commerce was competent enough in offering different ways to pay for the groceries. The following quote illustrates sufficient paying methods. The participant does not even 
remember which payment methods the electronic commerce offers, because she was satisfied with one, she used.

"I consider the systems adequate .. but I don't remember them. It is less hassle for my part."

One participant spoke about the possibilities of deceptions during payment and the use of cash-on-delivery payment method to prevent this happening. She noted that electronic commerce can be trusted if it has competent payment method.

Furthermore, the participants considered the appearance of the product deliverer and the opportunity to cancel or change the delivery as features of a competent electronic commerce. The next quote demonstrates one participant's view on a competent product deliverer.

"The product deliverer should be customer service-minded ... I mean to be kind and normal and he should also do what is agreed ... you know, hold to the delivery time and so on .. well, those are the things which affect the most ... whether it is pizza or anything elese that is delivered home, it depends on what the person is like ... whether he is kind or not."

Majority of the participants also perceived the opportunity to cancel or change the delivery as a feature of a competent electronic commerce.

"Yes, I expect to cancel the delivery because it is my right as a customer."

Some of the participants also viewed this opportunity as an attribute to competence but acknowledged the rule that order cannot be changed once the product is already shipped.

"In as much as I want it ... the product cannot be cancelled once it is already given to the deliverer."

In contrast, changing the product order without the consumer's permission annoyed the interviewees, because the electronic commerce they use sometimes 
changed the product and did not inform the interviewees about the change. Therefore, the electronic commerce was considered a bit incompetent. When asked about anything that happened unexpected during the process, they were explicate about changing of products without notification.

"Some products have ... some products have been replaced without notification ... they have only informed me about the change after I received it." (Participant 8)

They were asked about what they feel after receiving a totally different product and urged:

"Well, of course they could call if they change something... But actually, they have been good products and it has not irritated me much... But if they can't deliver even the replacement, then they should call and inform me".

Furthermore, the quality of perishable goods and the accuracy of delivery time were something the participants did not consider positive regarding the electronic commerce competence. The quality of perishable goods, for example, made the participants suspicious and they did not want to order those.

"If I were to order fresh products, I would be very cautions.... I would feel a bit suspicious about the quality of the products, because you can't see the fresh products like vegetable or meat".

Also, the accuracy of the deliver time offered by the electronic commerce did not please the participants:

"I lost my trust to a certain e-tailer once the delivery time is inaccurate. If they promise this time, then, the product should be delivered on time. If not, I would not buy again."

One competence-related issue was considered either positive or negative among the interviewees. That was the price level of the products. Some of the interviewees considered the process of the products competent. On the contrary, 
some said the price level is too high and therefore, they considered the electronic commerce incompetent.

"You could expect that the price is higher since it is from online shopping. It is more suspicious if the product is lower that the price of those sold in the malls."

"If I think the tag is overpricing. I would not buy it. I lose my interest on that e-tailer."

\section{Benevolence}

Benevolence means that someone believes the other party will notice his/her interest (Selnes \& Gonhaug, 2000; Wang \& Jap, 2017), for example, the consumer can assume that the e-vendor will deliver ordered products in the most convenient way for the consumer (Lee, Sirgy, Brown \& Bird, 2004).

Three issues emerged in the benevolence dimension that emphasizes the trustworthiness of the electronic commerce. First is the response to feedback. The participants stressed that if some problems occurred and they needed to give feedback to the electronic commerce, they wanted a fast response in order to solve the problem. That reflects the benevolence of the electronic grocery shop. If a response to the participants' feedback was given immediately, the participants felt the electronic commerce is really thinking about their best. In contrast, the electronic commerce was considered untrustworthy if the participants did not get any response at all, or if it took a lot of time to answer their question. Some of the participants also said they would not use services provided by such a company again. The next quote illustrates the issue.

"Well, I think it's always positive if you are contracted personally, either via email or telephone... you know nowadays, everyone is quite busy like I am too, so perhaps I would e-mail... Then I would like to have an answer explaining what they are going to do with my problem and when and how they are going to fix.... Of 
course, if they cannot fix the problem, I would like to have an explanation of why the problem can't be fixed."

Second issue was related to subjective satisfaction. This addresses whether the participant likes interacting with the online store. They believed that the electronic commerce is highly benevolent if sufficient interaction was made between the buyer and the vendor. That in turn affects their trustworthiness on the electronic commerce.

"I can be satisfied with the products if most of the time, I could interact with the e-tailer.... I could check easily the updates on new products."

Last issue was related to the usability of the products. The participants believed that the act of benevolence was thought to be result of negligence in the part of the e-tailer. This means that the user could not ask for any queries once the product fulfills the customer's expectation. If the products are usable, then, there would be smooth delivery of goods, this affects the buyer' trustworthiness on evendors.

"The product descriptions should be accurate and detailed so there are no surprises when the product finally reaches the customers like me. Why should I contact the e-tailer if my product is good?"

\section{Integrity}

Integrity means that someone can believe the other party acts ethically, does not tell lies, and keeps promises (Castillo, Mollenkopf, Bell \& Bozdogan, 2018). For example, the consumer can assume that the e-vendor does not overcharge or misuse his/her credit card (Randall, Baitalmal, Hawkins, \& Coyne, 2014). The integrity dimension revealed two issues concerning the trustworthiness of an electronic commerce. The participants mentioned that they need some explanations about how their personal information is used. If no explanations were offered, the participants did not consider the electronic commerce trustworthy, or did not use the service, because they were not sure who is going to get access to 
their personal information and where or how it is going to be used. This refers directly to the integrity of an electronic commerce. When asked about the services that required registration, one participant urged:

"Uhm... I think they are ok, if there is clear explanation of how they are going to use my personal information... I mean... they have to tell me if my personal information is going to be used in some other registers, too."

Another issue that appeared in the integrity dimension was information about the service provider, products and prices. Information about the services provider was mentioned by many participants. They also said they search for the information actively. Actually, it seems that the information about the service provider is a basic requirement that the participants wanted to find on the services provider's web site. Some of the participants also emphasized the reliability of the information, namely that the process and the quality of the products was a promised on the electronic commerce web site. The following quote illustrates the importance of information from one participant's point of view.

"The important features... well, you know... basic reliability... that is important. The of course... if they say a product costs X peso and the delivery fee is $X$ pesos, then, there should be the same amount on the invoice, too... and quality is also important."

Presented in Table 1 is the summary of themes and sub-themes which were generated from the interviews. As shown in the table, eight competence-related sub-themes were generated namely sufficient payment methods, sufficient home delivery of products, appearance of the product deliverer, opportunity to cancel or change the delivery, changing the product order without the consumer's permission, quality of perishable goods, accuracy of delivery time, and the price level of the products. There were three benevolence-related sub-themes namely, response to feedback, subjective satisfaction and usability. Lastly, two integrityrelated sub-themes were formulated, namely how their personal information is used and information about the service provider, products and prices. 
Table 1. Analysis

\begin{tabular}{|l|l|}
\hline Major Themes & Sub-themes \\
\hline \multirow{5}{*}{ Competence } & Sufficient payment methods \\
\cline { 2 - 2 } & Sufficient home delivery of products \\
\cline { 2 - 2 } & Appearance of the product deliverer \\
\cline { 2 - 2 } & Opportunity to cancel or change the delivery \\
\cline { 2 - 2 } & $\begin{array}{l}\text { Changing the product order without the consumer's } \\
\text { permission }\end{array}$ \\
\hline & Quality of perishable goods \\
\hline & Accuracy of deliver time \\
\cline { 2 - 2 } Benevolence & Price level of the products \\
\hline \multirow{4}{*}{ Integrity } & Response to feedback \\
\cline { 2 - 2 } & Subjective satisfaction \\
\cline { 2 - 2 } & Usability \\
\hline & How their personal information is used \\
\cline { 2 - 2 } & $\begin{array}{l}\text { Information about the service provider, products and } \\
\text { prices }\end{array}$ \\
\hline
\end{tabular}




\section{CONCLUSION AND RECOMMENDATION}

In this study, the researchers discussed the perceptions of the online customers on the trustworthiness of online businesses. According to the thematic results, the researchers found eight (8) subthemes under competence, three (3) in benevolence, and two (2) in integrity which are all related characteristics defining the trustworthiness of the online business. The findings of this study revealed several new attributes related to the word "trustworthiness" (e.g. sufficient payment methods, response to feedback, how personal information is used, etc.) which can be useful in future studies.

As to conclude, the trustworthiness of electronic commerce could be measured by the presence of three themes in the study: competence, benevolence and integrity. In the first theme, online customers could tell if the online business is trustworthy if the business possesses proper system in requesting payments and reasonable prices of the products being offered. Also, customers ground the trustworthiness of electronic commerce in terms of its delivery system. This dwell, specifically, on the accuracy of the business' deliveries in terms of the delivery location and time as well as the decorum and attitude of the product deliverer. Moreover, the business is competent if it lets the customers to cancel their orders and if it does not change the ordered product of the customers upon giving the delivery. Lastly, a trustworthy online business maintains the quality of their products offered especially the perishable goods.

Focusing to the next theme, a trustworthy electronic commerce must always respond to their customers and address their concerns towards the product or business itself. Additionally, the satisfaction and fulfillment brought by the products of online business make the business trustworthy. For the last theme, the trustworthiness of the online businesses mainly revolves around the information used in the transaction. The customers can usually tell if the business is trustworthy or not if it utilizes the personal information of the customers in an ethical manner and if the business itself provides adequate information about its firm, its products, and its price levels. 
Based on the preceding discussion, the researchers argue that the perceived trustworthiness of electronic commerce is based from its competence, benevolence, and integrity.

\section{Recommendation}

The researchers recommend other online customers who are used to shop online to personally and subjectively assess the online businesses they shop in terms of their competence, benevolence, and integrity. Using the findings of this study could be a functional guide for them to know if the sites they visit online are trustworthy or not; hence, reducing the possibilities that they would get scammed or feel unsatisfied by their requested orders. Furthermore, the researchers recommend the online sellers to review the researchers' findings so that they would know their lapses and shortcomings towards serving their customers. In this manner, the online sellers could raise their sales and acquire more long-term customers in their business. 


\section{REFERENCES}

Alipio, M. (2020). Predicting Academic Performance of College Freshmen in the Philippines using Psychological Variables and Expectancy-Value Beliefs to Outcomes-Based Education: A Path Analysis. https://doi.org/10.35542/osf.io/pra6z

Alipio, M. (2020). Academic Adjustment and Performance among Filipino Freshmen College Students in the Health Sciences: Does Senior High School Strand Matter?. https://doi.org/10.35542/osf.io/xq4pk

Bagaforo, N. C. (2017, February 2). Online business. Retrieved from https://www.sunstar.com.ph/article/123951

Cayon, M. (2018, December 21). E-commerce boosts sales of Davao small biz owners. Retrieved from https://businessmirror-com-ph.cdn.ampproject.org

Castillo, V. E., Mollenkopf, D. A., Bell, J. E., \& Bozdogan, H. (2018). Supply Chain Integrity: A Key to Sustainable Supply Chain Management. Journal of Business Logistics, 39(1), 38-56. doi:10.1111/jbl.12176

Changchit, C. (2006). Consumer perception of online shopping. Issues in Information System, $\quad$. Setrieved from https://www.google.com.url?sa=t\&source=web\&rct=j\&url=http://iacis.org/iis /2006/Changchit.pdy\&ved=2ahUKEwikuM32kP3gAhWlylsBHSzsCu8QFjA AegQIBBAB\&usg=AOvVaw2c0n1TXP2bioxW7s5V

Cox, A. (2001). Understanding Buyer and Supplier Power: A Framework for Procurement and Supply Competence (Vol. 37).

Crossman, A. (2018, September 28). Understanding purposive sampling: An overview of the method and its applications. Retrieved from https://www/thoughtco.com/purposive-sampling-3026727 
Diangson, L. (2014, December 15). 10 internet problems Filipinos are facing nowadays. Retrieved from https://www.yugatech.com/the-internet/10internet-problems-filipinos-are-facing-nowadays/

Derwik, P., \& Hellstrom, D. (2017). Competence in supply chain management: a systematic review. Supply Chain Management: An International Journal, 22(2), 200-218. doi:10.1108/SCM-09-2016-0324

Domingo, K. (2017, Septemeber 23). 'Trust' issues hold back Philippine ecommerce boom. Retrieved from https://news.abscbn.com/business/09/23/17/trust-issues-hold-back-philippine-eecommerce-boom

Folarin, T., \& Ogundare, E. (2016). Influence of customers' perceived risk on online shopping intention in Malaysia's apparel industry. International Journal of Information System and Engineering, 4. doi: 10.24924/ijise/2016.11/v4.iss2/69.81

Jara, M. S. (2018, May 14). Davao City taps online platform to help farmers with direct sales. Retrieved from https://www.bworldonline.com/davao-city-tapsonline-platform-to-help-farmers-with-direct-sales/

Karthikeyan, Dr. G. (2016). Problems faced by online consumers. International Journal of Current Research and Modern Education, 1. Retrieved from www.rdmodernresearch.com

Khan, A. (2016). Electronic commerce: A study on benefits and challenges in an emerging economy. Global Journals Inc. (USA), 16. Retrieved from http://creativecommons.org/licenses/by-nc/3.0/

Kim, D. J., Ferrin, D. L., and Rao, H. R. (2008). A trust-based cpnsumer decisionmaking model in electronic commerce: The role of trust, perceived risk, and their antecedents. Decision Support System, 44, 544-564. Retrieved from https://doi.org/10.1016/j.dss.2007.07.001 
Lanford, P., \& Hübscher, R. (2014). Trustworthiness in e-commerce. Proceedings of the 42nd Annual Southeast Regional Conference on - ACM-SE 42. doi: $10.1145 / 986537.986614$

Lee, D.-J., Sirgy, M. J., Brown, J. R., \& Bird, M. M. (2004). Importers' Benevolence toward their Foreign Export Suppliers. Journal of the Academy of Marketing Science, 32(1), 32-48. doi:10.1177/0092070303254382

Mack, S. (n.d.). The Commitment-Trust Theory of Relationship Marketing. Small $\begin{array}{lllll}\text { Business } & - & \text { Chron.com. } & \text { Retrieved from }\end{array}$ http://smallbusiness.chron.com/commtheory-relationship-marketing65393.html

Mahnke, R., Benlian, A., and Hess, T. (2015). A grounded theory of online shopping flow. International Journal of Electronic Commerce, 19:3, 54-89. Doi: 10.1080/10864415.2015.1000222

Marcelo, P. C. (2018, January 8). The internet even slower down South. Retrieved from https://www.bworldonline.com/internet-even-slower-down-south/

Palinkas, L. A., Horwitz, S. M., Green, C. A., Wisdom, J. P. (2013). Purposeful sampling for qualitative data collection and analysis in mixed method implementation research. Administration and Policy in Mental Health and Mental Health Services Research. doi: 10.1007/s10488-013-0528-y

Ozlen, M., Mekic, E., and Kumbara, E. (2014). Perceived benefits of e-commerce among manufacturing and merchandising companies. International Journal of Academic Research in Economics and Management Sciences, 3. doi: 10.6007/IJAREMS/v3-i2/676

Pennanen K., \& Paakki, M. (2006). A qualitative analysis of consumers' perceptions of the trustworthiness of e-commerce. Frontiers of E-business Research 2006. Retrieved from https://www.researchgatenet.cdn.ampproject.org 
Randall, W., Baitalmal, M., Hawkins, T., \& Coyne, A. (2014). Sustainable integrity: how reverse auctions can benefit suppliers in emerging markets. Supply Chain Management: An International Journal, 19(2), 126-141. doi:10.1108/SCM-06-2013-0184

Rouse, M. (2019, February). e-commerce (electronic commerce or EC). Retrieved from https://searchio.techtarget.com/definition/e-commerce

Segovia, O. W. (2016, October 31). Unfinished business: Why e-commerce in the Philippines is falling behind. Retrieved from https://medium.com/startupph/chronicles/unfinished-business-why-ecommerce-in-the-philippines-is-falling-behind-bc6087796bc3

Selnes, F., \& Gonhaug, K. (2000). Effects of Supplier Reliability and Benevolence in Business Marketing. Journal of Business Research, 49(3), 259-271. doi:https://doi.org/10.1016/S0148-2963(99)00017-X

Safari, A. (2012). Customers' international online trust - Insights from focus group interviews. Journal of Theoretical and Applied Electronic Commerce Research, 7, 59-72. doi: 10.4067/S0718-18762012000200007

Shafiyah N., Alsaqour R., Shaker, H., Alsaqour, O., and Uddin, U. (2013). Review on electronic commerce. Middle-East Journal of Scientific Research 18, 9. doi: 10.5829/idosi.mejsr.2013.18.9.12421

Shoup, M. (2018, May 22). Consumers have trust issues with online shopping that can be remedied. Retrieved from https://www.foodnavigatorusa.com/Article/2018/05/22/Consumers-have-trust-issues-when-it-comesto-online-shopping-that-can-be-remedied-says-Mintel

Sivanesan, R. (2017). A study faced by customers in online shopping with special reference to Kanyakumari District. International Journal of Research of Management \& Business Studies, 4. Retrieved from www.ijrmbs.com 
Tamturk, V. (2017, September 1). Online shoppers are increasingly concerned about their privacy. Retrieved from https://www.cms-connected.com/NewsArchive/August-2017/Online-Shoppers-are-Increasingly-Concerned-abouttheir-Privacy

Toral, J. (2016, January 5). Delivery delay hurts Philippines e-commerce sector. Retrieved from https://digitalfilipino.com/delivery-delay-hurts-philippines-ecommerce-sector/

Umeogu, B. (2012). Source credibility: A philosophical anaylsis. Open Jounral of Philosophy, 2, 112-115. Retrieved from http://dx.doi.org/10.4236/ojpp.2012.22017

Utz, S., Kerkhof, P., and Bos, J. (2011). Consumers rule: How consumer reviews influence perceived trustworthiness of online stores. Electronic Commerce Research and Applications, 11, 49-58. Retrieved from https://doi.org.10.1016/j.elerap.2011.07.010

Vaghela, P. S. (2014). A study on the consumer perception towards online shopping. International Journal of Technology Marketing, 12. Retrieved from

https://www.researchgate.net/publication/305751897_A_STUDY_ON_CO NSUMER_PERCEPTION_TOWARDS_ONLINE_SHOPPING

Vicente, J. (2014). Special report: The state of e-commerce in the Philippines. Retrieved from http://www.imadigitalmarketer.com/blog/state-ecommerceph

Wang, Q., \& Jap, S. (2017). Benevolent Dictatorship and Buyer-Supplier Exchange (Vol. 78).

Winnie, P. (2014). The impact of trustworthiness and customer e-loyalty and esatisfaction. International Journal of Academic Research in Business and Social Sciences, 4. doi: 10.6007/JJARBSS/v4-i3/718 
Zhang, X., \& Tang, Y. (2006). Customer perceived e-service quality in online shopping. Division of Industrial Marketing and E-commerce. doi:1653-0187 